\title{
Impact of solar reflectance of wall and road on outdoor thermal comfort - experimental study in a street canyon setup
}

\author{
Kiran Kumar D E V S ${ }^{1,2}$, Man Pun Wan ${ }^{1,2^{*}}$, Mandi Zhou ${ }^{2}$, Yongping Long ${ }^{2}$, and Bing Feng \\ $\mathrm{Ng}^{1}$ \\ ${ }^{1}$ School of Mechanical and Aerospace Engineering, Nanyang Technological University, Singapore \\ ${ }^{2}$ Energy Research Institute @NTU, Nanyang Technological University, Singapore
}

\begin{abstract}
Thermal environment in an urban street canyon is primarily affected by prevailing air conditions, wind flow, solar radiation as well as thermal properties of the surrounding urban structures and pavement surfaces that affect the reflection, absorption and re-emission of solar radiation. Experiments were conducted in a 1:5 scale test setup consisting of North-South oriented street canyon (height to width ratio 1.7) located in Singapore. Test cases covering two levels solar reflectance of walls $(0.35$ and 0.57$)$ and road (0.12 and 0.55$)$ were conducted in a three-month period. Environmental parameters including direct beam and diffuse solar radiation, net radiation (incoming and outgoing shortwave and longwave radiation) and wind speed were continuously measured at the top of the canyon. Thermal comfort parameters including air temperature, relative humidity, air velocity and globe temperature were also monitored continuously inside the street canyon. When the solar reflectance of canyon surfaces increases, mean radiant temperature (MRT) reduces by up to $1.2^{\circ} \mathrm{C}$ during daytime and $2.5^{\circ} \mathrm{C}$ during the night. Such reduction leads to reduced occurrence of heat stress by $34 \%$ and $42 \%$ during the day and night times, respectively, as measured by the universal thermal comfort index (UTCI). This paper further discusses the effect of longwave radiation on MRT in the street canyon due to changes in canyon solar reflectance.
\end{abstract}

\section{Introduction}

The thermal environment of an urban area depends on the heat transfer mechanism between different types of built-up surfaces as well as heat emission sources in the surrounding area. There are enough studies highlighting a strong correlation between urban morphology and increased air temperatures in urban areas especially during night times [1]. Primarily, the increased air temperatures could be estimated by knowing the amount of absorbed solar irradiation and the re-emitted infrared radiation from built-up surfaces. Low solar reflectance of built-up surfaces can also elevate outdoor temperatures by means of convective and radiative heat exchanges. In fact, it was reported that infrared radiation from

* Corresponding author: mpwan@ntu.edu.sg 
roads that contributes to warming up of surrounding air is equivalent to over half of the anthropogenic heat generated from commercial buildings [2].

Simulation studies carried out by Pearl mutter et al. [3] show that pedestrian energy balance is predominantly affected by radiative exchange with urban fabrics rather than with air temperature. In this context, the aspect ratio of urban street canyons contributes significantly to surface and air temperatures and the resultant energy fluxes. It was observed that solar flux reflected from street canyon was only about $1 / 3$ the total flux during the day while longwave flux emitted from the canyon during the night was much higher than that from roof surfaces [4]. As such, integration of highly reflective cool surfaces within the built environment can be seen as a cost effective solution to offset the urban heat island effect. In this paper, the impact of outdoor thermal comfort parameter due to changes in solar reflectance of the wall and road surfaces in a street canyon setup will be investigated through an experimental setup.

\section{Methodology}

\subsection{Experimental setup}

The test setup comprises of a street canyon setup that is erected within the Nanyang Technological University (NTU) campus in Singapore using two prefabricated cement concrete test houses as shown in Fig. 1. Each test house is of size $2.5 \mathrm{~m}(\mathrm{~L}) \times 2 \mathrm{~m}(\mathrm{~B}) \times 3$ $\mathrm{m}(\mathrm{H})$. The two houses are $1.8 \mathrm{~m}$ apart to represent a typical street between two high-rise buildings in a 1:5 scale. The orientation of the street is aligned in the North-South direction with a height to width $(\mathrm{H} / \mathrm{W})$ aspect ratio of 1.7 . Thicknesses of the wall and roof slabs of the test houses are both $150 \mathrm{~mm}$ with a density $2240 \mathrm{~kg} / \mathrm{m}^{3}$, a thermal conductivity of 1.44 $\mathrm{W} / \mathrm{mK}$ and a specific heat capacity of $0.75 \mathrm{~kJ} / \mathrm{kgK}$. An artificial road pavement is constructed over the soil in-between the two test houses. A $25-\mathrm{mm}$ thick steel plate is placed over the soil followed by a $100-\mathrm{mm}$ thick concrete layer. Top surface is finished by a 4-mm thick mineral coated bitumen top layer to simulate an asphalt concrete road surface. Total heat capacity of the artificial road pavement is $0.40 \mathrm{~kJ} / \mathrm{m}^{2} \mathrm{~K}$.

\subsection{Instrumentation}

An array of instruments are employed in this study as shown in Fig. 1. At the top of the canyon, a net radiometer (Kipp\& Zonen CNR4), a cup anemometer (Metone 034B Windset) and a thermopile sensor (Hukseflux HFP01) are installed and connected to data loggers (Campbell Scientific CR6 \& CR800). The net radiometer has a total of four sensors for incoming and outgoing shortwave $(0.3-3 \mu \mathrm{m})$ and longwave $(3-30 \mu \mathrm{m})$ radiation. In the middle of the street canyon, a thermal comfort station is positioned at a height of $0.35 \mathrm{~m}$ to represent a human body. It consists of a $5 \mathrm{~mm}$ diameter black globe with a PT100 sensor inside (Delta Ohm TP876.1.I), a thermohygro sensor with solar radiation shield (Delta Ohm HD9008TRR \& HD9007A-1) and an omni-directional air velocity probe (Delta Ohm HD403TS2) connected to an outdoor type general purpose data logger (HD35EDLWH.E). Surface temperature of the wall and road surfaces was measured using PT100 (Madgetech SM93) connected to data loggers (Madgetech quadRTD). In addition to these parameters, rainfall and air temperature were collected from a weather station maintained by the National Environmental Agency (NEA) of Singapore at about $600 \mathrm{~m}$ away from the test site. 


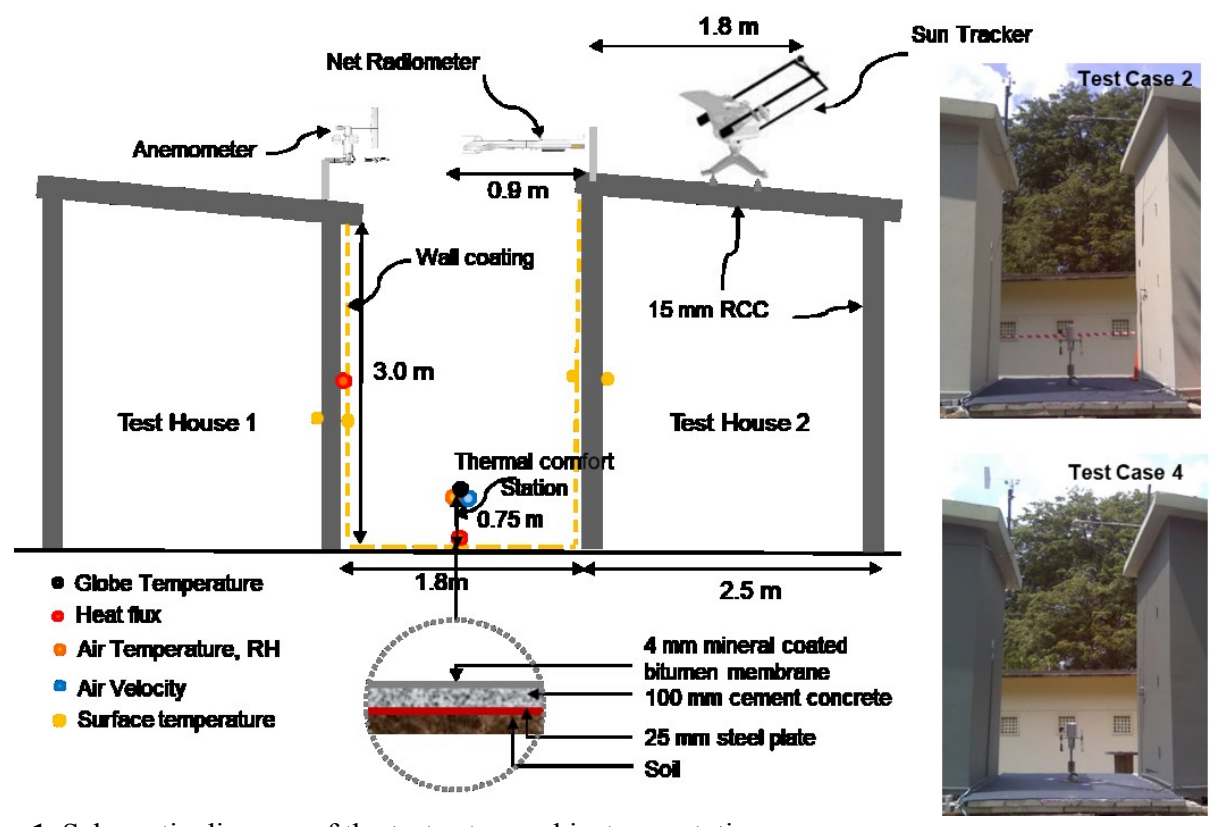

Fig. 1. Schematic diagram of the test setup and instrumentation

\subsection{Test cases}

Test cases covering two levels of wall solar reflectance $(0.35$ and 0.57$)$ and road solar reflectance $(0.12$ and 0.55$)$ were conducted from January to March 2018. The higher solar reflectance levels on wall and road surfaces were achieved by painting three layers of cool coating (Nippon Paint SolaReflect) on them (Case $1 \& 2$ ). Grey colour coating was used to give the lower solar reflectance level of walls (Case $3 \& 4$ ). The lower solar reflectance of road was attained by directly exposing the mineral bitumen surface. Solar reflectance $(\rho)$ of the wall and road surface was measured on site in accordance to ASTM C1549 [5] using a portable solar spectrum reflectometer (SSR-ER version 6).

As there are two levels of wall and road solar reflectance used in the tests, the effect of these factors under varying solar irradiation conditions will be analysed using an applied statistical technique called $2^{\mathrm{k}}$ factorial design. It is used to find the effect of different factors on an output or response, which in this case is the mean radiant temperature (MRT).

Solar reflectance $\left(C_{\rho}\right)$ and thermal emittance due to heat storage $\left(C_{\varepsilon}\right)$ of the entire canyon in each test setup was calculated based on Eqs. 1 \& 2, using the incoming shortwave $\left(\mathrm{SW}_{\text {in }}\right)$, outgoing shortwave $\left(\mathrm{SW}_{\text {out }}\right)$, incoming longwave $\left(\mathrm{LW}_{\text {in }}\right)$ and net longwave $\left(\mathrm{LW}_{\text {net }}\right)$ measured by the net radiometer (Table 1). Each of the tests were conducted for at least five days, such that each test covers five non-rainy days. The data obtained from these five non-rainy days will be used for subsequent data analysis. The abovementioned thermal comfort and environmental parameters were monitored at 5minute intervals during the entire test duration.

$$
\begin{gathered}
C_{\rho}=\frac{S W_{\text {out }}}{S W_{\text {in }}} \\
C_{\epsilon}=\frac{L W_{\text {net }}}{L W_{\text {in }}}
\end{gathered}
$$


Table 1. Detail of surface properties measured on site for four test cases.

\begin{tabular}{|c|c|c|c|c|}
\hline Setup & $\begin{array}{c}\text { Wall } \\
\text { Reflectance }\end{array}$ & $\begin{array}{c}\text { Road } \\
\text { Reflectance }\end{array}$ & $\begin{array}{c}\text { Canyon } \\
\text { Reflectance }\left(\boldsymbol{C}_{\boldsymbol{\rho}}\right)\end{array}$ & $\begin{array}{c}\text { Canyon } \\
\text { Emittance }\left(\boldsymbol{C}_{\varepsilon}\right)\end{array}$ \\
\hline Case 1 & 0.57 & 0.55 & 0.21 & 0.12 \\
\hline Case 2 & 0.57 & 0.12 & 0.19 & 0.13 \\
\hline Case 3 & 0.35 & 0.55 & 0.13 & 0.17 \\
\hline Case 4 & 0.35 & 0.12 & 0.12 & 0.17 \\
\hline
\end{tabular}

\section{Results and Discussions}

\subsection{Mean Radiant Temperature (MRT)}

Being located near the equator, Singapore (Latitude: $1^{\circ} 17^{\prime} \mathrm{N}$, Longitude: $103^{\circ} 50^{\prime} \mathrm{E}$ ) has tropical climate with high and uniform temperatures, high humidity and rainfall throughout the year. Out of five days of data collected in each test case, three sunny days were selected for analysis. Air temperature, relative humidity, air velocity and globe temperature data was used to derive MRT based on Eq. 3 [6]. Fig. 2 illustrates the distribution and frequency of the MRT (both during day and night) across the four test cases under similar sky conditions (intermediate sky condition with clearness index ranging from 0.46 to 0.57 ). The distribution trend shows that MRT inside the canyon increases (towards right) as the solar reflectance of wall and road decreases (towards down) both during the day (06:00 to 18:00 h) as well as the night (18:00 to 06:00 h). Statistical mean and median are also calculated for each case. It can be observed that the magnitude of increase in mean MRT is up to $1.2^{\circ} \mathrm{C}$ during daytime and $2.5^{\circ} \mathrm{C}$ during night time when the solar reflectance of the wall reduced from 0.57 to 0.35 .

$$
T_{m r t}=\left[\left(t_{g}+273\right)^{4}+\frac{1.1 \times 10^{6} \times V_{a}^{0.6}}{\epsilon_{g} \times D^{0.4}}\left(t_{g}-t_{a}\right)\right]^{0.25}-273
$$
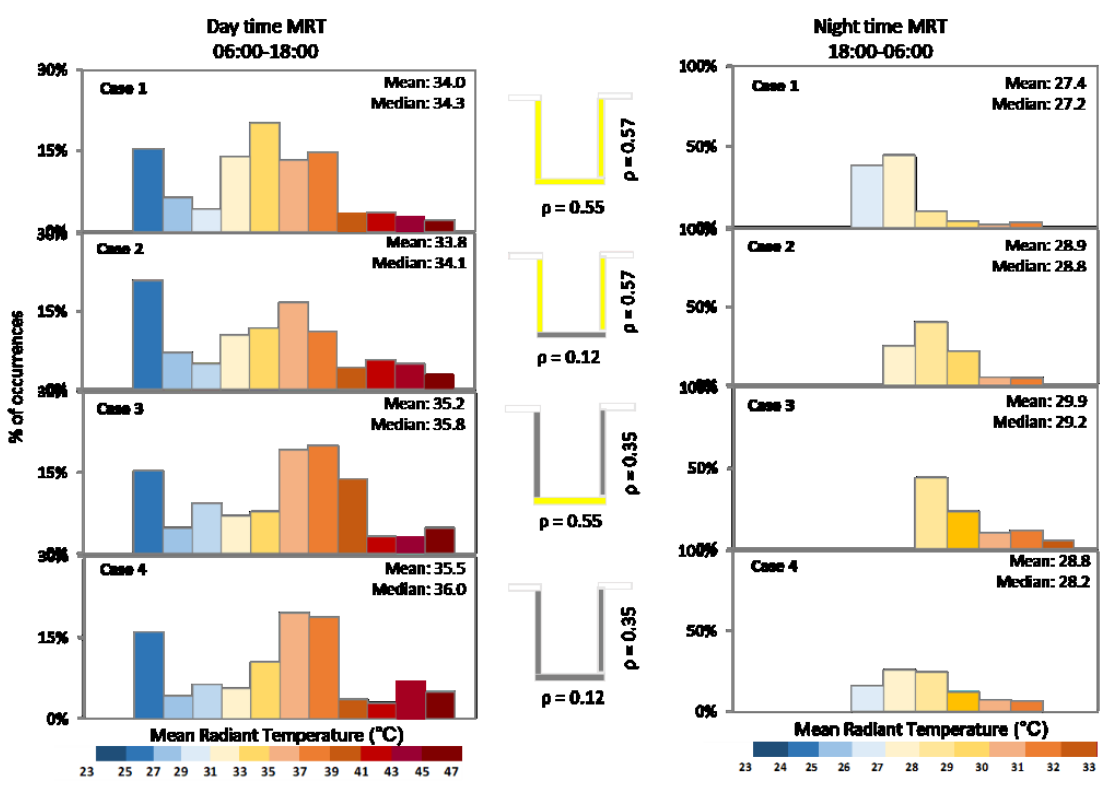

Fig. 2. Comparison of distribution of MRT among the four test cases. 


\subsection{Universal Thermal Comfort Index (UTCI)}

UTCI is expressed as an equivalent temperature of a reference environment the gives the same physiological response of a human. It is developed based on a multi-node model combining human thermal parameters with appropriate clothing models. The model is sensitive to small changes in the ambient conditions like temperature, solar radiation, humidity and wind speed and it is applicable well for wide range of climates. UTCI is selected for the analysis as it represents temporal variability of human strain conditions well as compared to other available indices such as the Physiological Equivalent Temperature (PET) and Effective Temperature (ET) [7]. Levels of heat stress perceived by human is determined as 'no stress' when $8 \leq \mathrm{UTCI} \leq 26$, 'moderate heat stress' when $26 \leq \mathrm{UTCI} \leq$ 32 , 'strong heat stress' when $32 \leq \mathrm{UTCI} \leq 38$ and as 'very strong heat stress' when $38 \leq$ $\mathrm{UTCI} \leq 46$ [8]. For the purpose of analysis in this paper, UTCI for each measurement point is determined using Eq. 4 [9]. As observed in Fig. 2, the increase in daytime mean MRT and night time mean MRT observed from test case 1 to 3 (when the wall solar reflectance is reduced from 0.57 to 0.34 ) is $1.2^{\circ} \mathrm{C}$ and $2.5^{\circ} \mathrm{C}$, respectively.

Although total solar irradiation on the test days selected for analysis is similar (difference $<10 \%$ ), the temporal variation of radiation intensity varied and therefore the hourly profile of measured MRT changed across the test cases. For this reason, daytime UTCI is correlated with the incident solar radiation and the night time UTCI with the air temperature for all the three days. Fig. 3 shows that the trend of daytime UTCI is lower in case of test case 1 compared to test case 3 . However, as the intensity of radiation increases, the difference in UTCI between test cases $1 \& 3$ becomes less. It could be understood that the UTCI is influenced by direct solar irradiation irrespective of the wall solar reflectance when the intensity of the irradiation is high during mid-day of the test. Fig. $3 b$ shows the correlation between night time UTCI and reference air temperature where in this case, the difference between the UTCI observed in the two test cases is lower as the reference air temperature is lower. This means that as air temperature reaches the daily minimum (which generally occurs between 04:00 to 06:00 h), the influence of heat storage due to low solar reflective wall (test case 3 ) on the UTCI has become insignificant.

$$
U T C I=3.21+0.872 * t+0.2459 * M R T-2.5078 * v-0.0176 * R H
$$
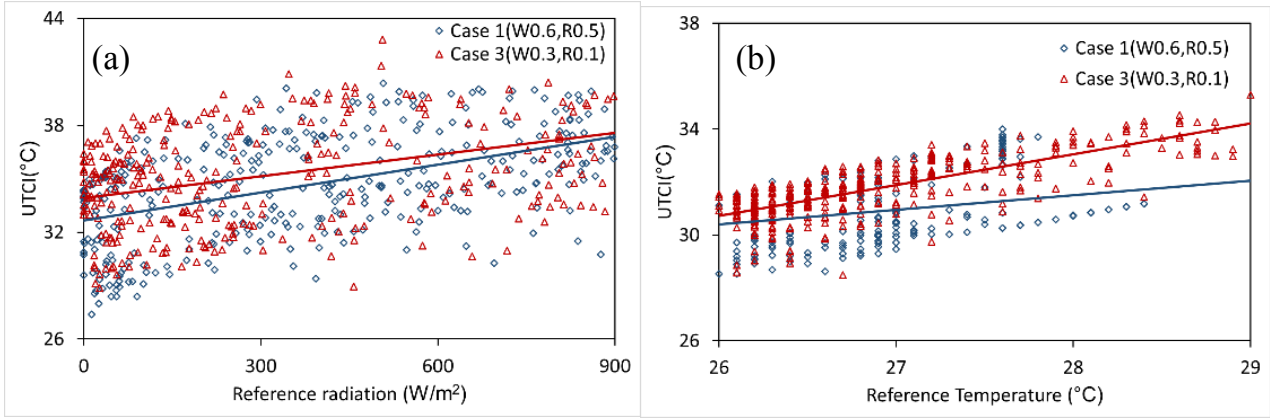

Fig. 3. (a) Correlation between daytime UTCI and solar irradiation, (b) Correlation between night time UTCI and reference air temperature.

Fig. 4 shows the distribution of different heat stress levels assessed based on UTCI, both for day and night time conditions for all the four test cases. Comparing test cases 1 and 3, high solar reflectance of wall in the former contributed to $34 \%$ reduction in very strong heat stress during daytime and $42 \%$ reduction in strong heat stress during night time. The higher 
MRT, which lead to higher heat stress in case of test case 3, could be attributed to the view factor of the measurement point with the surrounding wall and the road, as well as the intensity of emitted longwave (LW) and reflected shortwave (SW) from those surfaces.
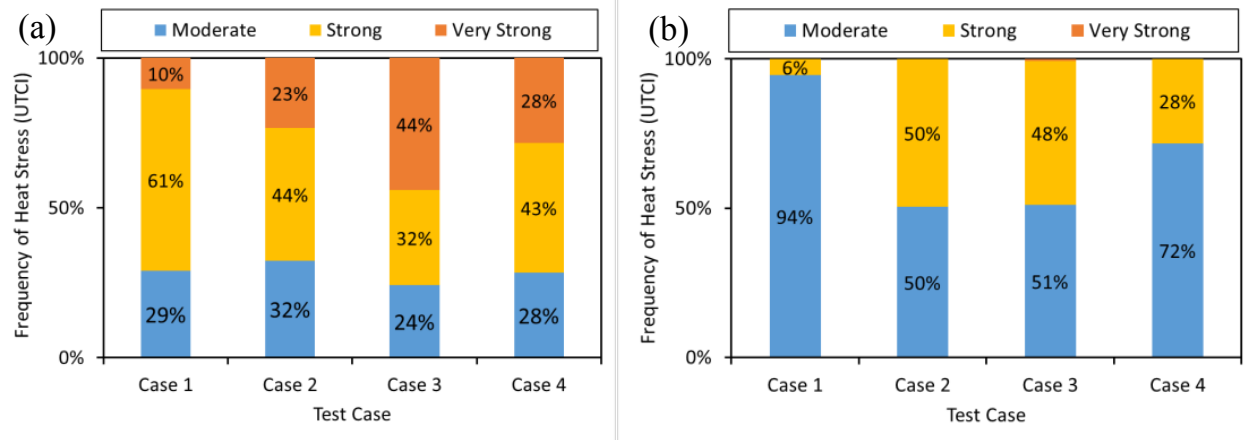

Fig. 4. Histograms showing frequency of heat stress levels among the test cases; (a) daytime UTCI, (b) night time UTCI

\subsection{Correlation between MRT and LW radiation}

MRT is directly related to LW radiation emitted from the canyon surfaces, especially in absence of direct solar radiation. Eq 5 determines MRT based on radiation parameters as given by VDI standard 3787-Part 2 [10].

$$
T_{m r t}=\left[\frac{1}{\sigma} \sum_{i=1}^{n}\left(E_{i}+a_{k} \frac{D_{i}}{\varepsilon_{p}}\right) F_{i}\right]^{0.25}
$$

The surface temperature data collected from test cases $1 \& 3$ is used to estimate LW radiation from the canyon surfaces and further correlate with the measured MRT. The correlation in the Fig. 5 shows higher night time MRT in test case 3 caused by higher LW emission is due to the higher wall surface temperature as compared to test case 1 . The heat absorbed and stored during daytime due to lower solar reflectance of wall surface in test case 3 remain almost throughout night, which ultimately resulted in higher MRT.

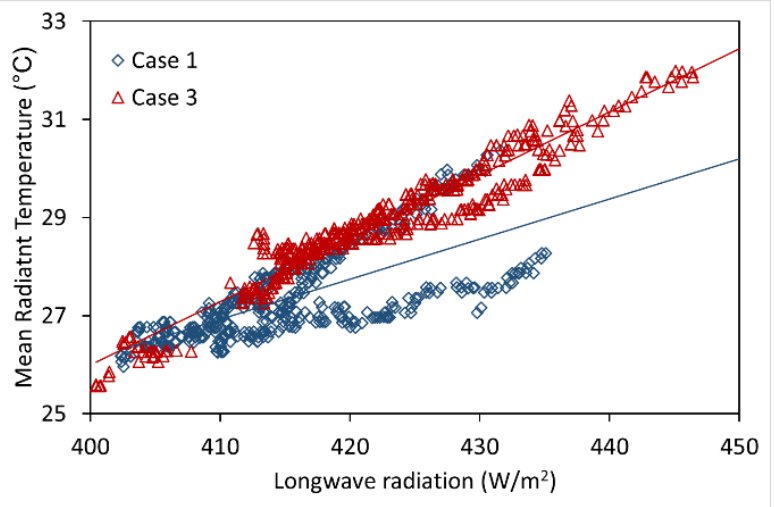

Fig. 5. Correlation between LW radiation and measured MRT for test cases $1 \& 3$ 
The analysis based on $2^{\mathrm{k}}$ factorial design shows that direct solar radiation under low solar reflectance of wall and road is the major factor affecting the MRT, followed by the effect of high wall reflectance under high solar irradiation conditions. It is important to note that the orientation of the street canyon is North to South, and hence the exposure of globe sensor to high solar irradiation is only during the mid-day. The aspect ratio of the canyon provides shades to the road for most part of the day. As observed in test case 3, high reflective road surface leads to increased amount of heat gain on the wall due to reflected SW radiation. This heat further increased the amount of LW and contribute to higher MRT. Similar observations were found in the theoretical studies carried out by Yaghoobian et al. [11].

\section{Conclusions}

Experiments were conducted in a North-South oriented street canyon set up in Singapore to study the impact of wall and road solar reflectance on thermal comfort in the street canyon. When the solar reflectance of the walls increases from 0.35 to 0.57 , mean MRT in the street canyon decreases by $1.2^{\circ} \mathrm{C}$ during daytime and by $2.5^{\circ} \mathrm{C}$ during night time. This leads to reduced occurrence of heat stress (as measured by UTCI) by over $34 \%$ and $42 \%$ during the day and night, respectively. Direct radiation has a prominent effect on the street canyon MRT during daytime regardless of the solar reflectance of the wall. The effect of reflected SW on the increase of MRT in case of high reflective wall was less compared to the effect of increase LW in case of low reflective wall. This was possible due to the shaded area and low aspect ratio observed in the North-South orientation of the street. This effect was evident when the measured MRT was correlated with longwave radiation for different solar reflectance of the wall. High reflective road surfaces lead to increased amount of heat gain on the low reflective wall due to reflected SW radiation, and lead to increase in MRT, whereas this effect was insignificant in the case of high reflective wall.

Acknowledgement: This work was financially supported by the National Research Foundation (NRF) of Singapore through Land and Livability National Innovation Challenge (L2 NIC) grant no. L2NICCFP2-2015-4.

\section{References}

1. R Rohinton and S Koen, Build. Res. \& Info, 46, 8 (2018)

2. T. Asaeda, V. Thanh C, A. Wake, Atm. Env., 30, 3 (1996)

3. D. Pearlmutter, P. Berliner, E. Shaviv, Build. and Env., 42, 2396-2409 (2007)

4. D. Pearlmutter, A. Bitan., P. Berliner, 33, 4143-4150 (1999)

5. ASTM C1549 16, ASTM International, West Conshohocken, PA (2016)

6. ISO 7726, International Organization for Standardization (1998).

7. K. Blazejczyk, Y. Epstein, G. Jendritzky, H. Staiger, B. Tinz, Int J Biometeorol.56 (3), 515-35 (2012)

8. P. Brode, D. Fiala, K. Bejczyk, I. Holmer, G. Jendritzky, B Tinz, G. Havenith, Int J Biometeorol, 56, 481-494( 2012)

9. K Blazejczyk, Prace I Studia Geograficzne WGST UV, 47. 275-283 (2011)

10. VDI 3787. Part 2, Beuth Verlag, Berlin (2008).

11. N. Yaghoobian, J. Kleissl, and E.S. Krayenhoff, J. Appl. Meteor. Climatol., 49, 332345 (2010) 